\title{
Preliminary Study on Human Host Factors Perpetuating the Transmission of Schistosomiasis in Endemic Community of Wudil, Kano State, Nigeria
}

\author{
Mahmud Ali Umar ${ }^{1^{*}}$, Umar Aliyu Umar², Mujitapha Lawal ${ }^{1}$, \\ Sani Muhammad Yahaya ${ }^{1}$ and Muhammad Salisu Inuwa ${ }^{3}$ \\ ${ }^{1}$ Department of Biology, Kano University of Science and Technology, Wudil, Kano State, Nigeria. \\ ${ }^{2}$ Department of Biochemistry, Ahmadu Bello University, Zaria, Nigeria. \\ ${ }^{3}$ Pharmacy Department, Federal Medical Centre, Birnin Kudu, Jigawa State, Nigeria.
}

\begin{abstract}
Authors' contributions:
This work was carried out in collaboration among all authors. Author MAU designed the study. Authors MAU and UAU performed the statistical analysis. Authors MAU and SMY wrote the protocol, author MAU and UAU wrote the first draft of the manuscript. Authors ML and MSI managed the analyses of the study. Authors SMY, ML and MSI managed the literature searches. All authors read and approved the final manuscript

Article Information

DOI: 10.9734/ARRB/2021/v36i830408

(1) Dr. Viduranga Y. Waisundara, Australian College of Business and Technology, Sri Lanka. Reviewers:

(1) Tayo Alex Adekiya, University of the Witwatersrand, South Africa. (2) Catherine Gordon, QIMR Berghofer Medical Research Institute, Australia. (3) Peerut Chienwichai, Chulabhorn College of Medical Science, Chulabhorn Royal Academy, Thailand. Complete Peer review History: https://www.sdiarticle4.com/review-history/65690
\end{abstract}

Original Research Article

Received 20 May 2021

Accepted 26 April 2021

Published 04 August 2021

\begin{abstract}
Objective: A cross-sectional study was conducted to determine the human host factors that contribute to the perpetuation of schistosomiasis transmission in endemic communities of Wudil, Kano State, Nigeria.

Methods: Information was derived from structured questionnaires supplemented with oral interviews, on perception of the community on the cause of urogenital schistosomiasis, using selfreported macrohaematuria, as the disease proxy, water-use practices, riverside urination and defaecation, and the choice for treatment of schistosome infection.

Results: Out of 139 study participants, the perceived causes of gross haematuria by the respondents were Excessive Salt Intake (41.73\%); Scorching Sun (20.86\%); Unknown (17.27\%);
\end{abstract}


Infection (10.07\%); Supernatural Force (5.86\%) and Water Contact (4.32\%). The respondents with self-reported terminal haematuria were $49.64 \%$; riverine water contact $75.54 \%$ and riverside contamination $65.41 \%$. Of the $72.46 \%$ of the respondents with gross haematuria who attempted for medication only $8.0 \%$ visited health facilities, while majority relied on traditional herbalists $(39.13 \%)$ and roadside medicine stores $(20.29 \%)$ for treatment. There was a strong association between riverine water contact and terminal haematuria (Odds Ratio: 6.09, 95\% Cl, 2.825-13.131, $\mathrm{P}<0.0001$; Relative Risk: $2.737,95 \% \mathrm{Cl}, 1.664-4.502, \mathrm{P}<0.0001)$.

Conclusion: Exposure to contaminated water as a result of socioeconomic activities, riverside, poor perception on the cause of the disease and lack of adherence to orthodox treatment of positive cases are the key promoters of schistosomiasis transmission in the study area. Excessive salt intake and scorching sun are the major perceived causes of haematuria among the study participants. This underpins the need for health education and other efficacious interventions for community awareness on the disease etiology which is central to effective elimination campaign.

Keywords: Schistosomiasis; haematuria; perception; water contact; healthcare-seeking behaviour.

\section{INTRODUCTION}

Human schistosomiasis is a waterborne neglected tropical disease (NTD) caused by the blood flukes of the genus Schistosoma. Schistosomiasis has been ranked by the World Health Organization (WHO) as the second most important parasitic disease after malaria, due to its prevalence and associated morbidity $[1,2]$. It is an endemic disease in tropical regions especially in resource-poor communities with global estimates of over 700 million people at risk and 260 million people suffering from the disease in 76 countries across Africa, Latin America, Middle East and Asia [2,3]. Schistosomes are sexually dimorphic and digenetic trematodes that require two hosts to complete their life cycle. The adult worms of Schistosoma haematobium live in the vesical plexus surrounding the urinary bladder of humans, the males carrying the females in their gynaecophoric canals. The females release eggs which pass through the tissues and enter the bladder. They are then passed to the exterior in the urine. The eggs released in water hatch and release miracidia larvae which find an appropriate snail intermediate host, penetrate and mature into a human-infective cercarial larvae. During this period, if they come into contact with human skin, they penetrate the body with the help of secretions from their penetration glands, and transform into a young adults called schistosomula. These young adults enter bloodstream and migrate to the liver via the lungs. Both male and female schistosomes attain full maturity in the liver, pair and move to the pelvic venous plexus where the females lay eggs to begin another life cycle. In the course of penetration and passage through the various tissues, some of the eggs get trapped in tissues of the genital and urinary systems. In the case of urogenital schistosomiasis where about $50 \%$ of the eggs are trapped in the wall of the bladder immune inflammatory response is elicited $[4,5,6]$. The resident inflammatory cells encapsulate the eggs which results in the formation of granulomatous lesions. In chronic cases the granulomas become fibrotic and later calcified. Common symptoms of Urogenital schistosomiasis (UGS) are urinary frequency, urgency, dysuria and terminal haematuria. This visible haematuria, or blood in the urine is the most feasible and often form the basis for epidemiologic diagnosis of UGS $[7,8]$.

In Nigeria, the most populous country in Africa and with significant number of water resources development projects, schistosomiasis is endemic with transmission influenced by several factors such as continuous water contact activities for socioeconomic purposes and anthropogenic faecal and urine contamination [9], coupled with prevailing snail vector abundance in endemic areas [10,11]. At least $91.4 \%$ of the population requiring treatment for schistosomiasis live in Africa [3]. Oladejo and Ofoezie [12], reported an endemicity of UGS in Nigeria with about $95 \%$ of the population lacking the knowledge about the mode of its transmission or prevention. Although mass chemotherapy with praziquantel $(\mathrm{PZQ})$ is the major control strategy for morbidity reduction in endemic areas, this has not been successful since the drug does not prevent post-treatment reinfection. Haematuria could serve as an index of endemicity of the disease which can be exploited for rapid assessment during control campaign [13,14]. Sustainable preventive measures for individuals at risk and multi-level contact control such as mass treatment with praziquantel, snail vector control and prevention of anthropogenic 
environmental contamination are of public health significance in order to curb schistosomiasis transmission in endemic areas. For successful public health interventions on infectious diseases with a view to reducing disease morbidities, and significantly blocking further transmission, proper understanding of the sociocultural belief, perception, awareness and healthcare-seeking behaviour of the community-at-risk is of immense importance. Therefore, the present study was designed to determine the human host factors that contribute to the perpetuation of UGS in endemic community of Wudil, Kano State, Northern Nigeria.

\section{MATERIALS AND METHODS}

\subsection{Study Area}

The study was carried out in Wudil Town, Wudil Local Government Area (LGA) of Kano State, which is located within the Sudan Savannah region of Nigeria, between the latitude $11^{\circ} 37^{\prime} \mathrm{N}$ and longitude $8^{\circ} 58^{\prime} \mathrm{E}$ [14]. The area is a lowland lying at an altitude of $413 \mathrm{~m}$ above the sea level. Wudil Town is a commercial centre located along the Kano Maiduguri Highway about $44 \mathrm{~km}$ away from Kano City. To the West it is bordered with Kano-Hadejia River which flows through the town. The inhabitants of Wudil community are predominantly Hausa/Fulani, with farming and animal husbandry being the dominant occupations. Wudil Market opens weekly and attracts people from within and outside the state for commercial activities thus accommodating people from different socioeconomic backgrounds [15]. The study area was chosen because of its location as a major riverine town with high frequency of daily water contact activities (WCAs) throughout the year [16]. There is a small body of literature on the epidemiology of UGS particularly with regard to the attitude and behaviour of the community towards treatment of the end-stream haematuria, or what they locally called Tsargiya, or Fitsarin jini, the most common morbidity and symptom of UGS in endemic settings.

\subsection{Study Population}

The study comprised 139 participants, out of which 108 were males and 31 were females and of different age classes who have voluntarily agreed to participate in the study after extensive oral explanation of the aim of the study. The study participants came from within and the neighbouring local government areas, and are predominantly Hausa-Fulani involved in various occupations such as trading, street vending, sand collection, irrigation farming and animal rearing. A significant number of the youth participants attended Almajiri school in the town. There were 150 study participants initially recruited out of which 11 were not included in the analysis either due to consent/assent withdrawal, lack of completeness or inconsistency of the data captured.

\subsection{Sample Size}

The sample size was determined using the formula of Cochran (2005), and on the basis of the UGS prevalence of $8.3 \%$ reported by Dawaki et al. [17], as follows:

$\mathrm{N}=\mathrm{Z}^{2}(1-P) / \mathrm{d}^{2}$, where:

$\mathrm{N}=$ Sample size; $\mathrm{Z}=1.96$ (at $95 \%$ confidence level); $P=$ Expected prevalence (8.3\%); $d=$ Allowable error (5\%)

Thus, sample size $(\mathrm{N})=116$

The minimum sample size $(\mathrm{N})$ was 116 which was adjusted to 150 study participants.

\subsection{Questionnaire Survey}

This cross-sectional study adopted a convenience sampling technique in the administration of questionnaires. Study participants comprised individuals who were sighted around the riverine area of Wudil River in Wudil Town without considering the purpose of their being there. Individuals were enrolled in the study after informed consent. Underage participants who assented to the study were followed to their homes to seek consent of their parents or guardians. A self-reported gross haematuria was used as a proxy for urogenital schistosomiasis. A structured questionnaire was pretested before it was finally administered as the main tool for the qualitative survey, in order to obtain information on the participants' sociodemographics and the behaviour related to disease transmission. Where necessary, the questionnaire administration was supplemented with oral interview in the local language, Hausa, in order to facilitate appropriate response. Information contained in the questionnaire was also translated into the local language to ease understanding of the respondents. The Hausa version of the questionnaire was tested on the school-age children from the neighbouring 
community. Appropriate adjustment was made before it was finally back-translated into English and then adopted for the study. The riverside contamination was determined by assessing open field defaecation and urination by nonparticipant observational study. The subjects from which the study participants were drawn were observed for the environmental contamination with faeces or urine close to the perimeter of the water body, for $4 \mathrm{hrs}$ between $11 \mathrm{am}$ and $3 \mathrm{pm}$ every day for 3 days. This observation period was believed to be the peak period of WCAs in rural endemic settings and, when the risk of schistosomiasis transmission is highest $[11,18]$. Afterward, the assessment of riverside contamination was confirmed from the respondents during the questionnaire survey.

\subsection{Data Analysis}

Data were analysed using descriptive statistics such as simple frequencies, means and percentages. To determine any association between risk factors and haematuria, achisquare test was carried out at $5 \%$ probability level. The strength of the association was determined using odds ratio (OR) and relative risk(RR). All data analyses were run by Microsoft Excel, 2016.

\section{RESULTS}

\subsection{Sociodemographics}

The results in Table 1 present information on sociodemographics of the study participants. Out of 139 participants in this cross sectional study, $108(77.7 \%)$ were males and $31(22.3 \%)$ were females. Prevalence of self-reported haematuria was higher in males $(59.26 \%)$ with a significant association $(P<0.001)$. The overall self-reported prevalence of haematuria, used as a proxy for UGS, is $49.64 \%$. The mean age of the study subjects was 28 \pm 1.34 years (age range: 7-68 years). Individuals within the age-groups 0 to 30 years reported more gross haematuria than older age-groups, which also reduced progressively with advancing age. The age-group 11-20 years recorded highest prevalence of haematuria $(72.97 \%)$ while individuals aged $51-60$ years had the least $(16.67 \%)$. Prevalence of haematuria was found to be significantly associated with age-group of the respondents $(P<0.001)$. Moreover, the respondents were involved in different types of occupation, with water-based type recording higher frequency of $52.52 \%$. Of the four water-based occupations observed, respondents involved in commercial laundry had a highest prevalence of haematuria (63.64\%); studentship as non-water-based had a higher haematuria prevalence of $61.29 \%$ (Table 1 ).

Education status, as a sociodemographic factor for UGS transmission, is presented in Table 1. Majority (approximately, 55\%) of the respondents acquired at least primary school education, while only $7.19 \%$ attained tertiary education. However, a sizable number had been pupils or students of the Almajiri school, a traditional non-formal educational institution where individuals of Islamic faith in Hausaland learn Arabic/Qur'anic scripts. Only $16.55 \%$ of the respondents had never been to school or did not attend either formal or non-formal institution. The highest prevalence of haematuria $(61.54 \%)$ was observed in individuals with non-formal education (the Almajiri school pupils and students), followed by unlettered respondents $(52.17 \%)$. In addition, individuals who acquired tertiary education had lowest prevalence of reported haematuria during the study; education status of the respondents significantly varied with haematuria prevalence $(P<0.001)$.

\subsection{Perception, Water Exposure and Contamination}

The results of perception of the endemic community on the cause of UGS are presented in Table 2. Perception of the cause of the disease varied among the study subjects; infection (10.07\%), water contact (4.32\%), supernatural force $(5.76 \%)$, excessive salt intake $(41.73 \%)$, scorching sun $(20.86 \%)$ and unknown $(17.27 \%)$. The most perceived cause of UGS was excessive salt intake; water contact being the least (Fig. 1). In gender comparison, the trend was almost the same, except that in male respondents, supernatural force was the least perceived cause of the infection, while water contact was the least in females.

Types and intensities of water contact activities of the respondents are presented in Table 3. These include bathing, swimming, fishing, fetching, irrigation farming and clothes washing; swimming and personal clothes washing being the most frequent $(20.14 \%$ and $15.8 \%$, respectively). Water exposure intensity varies with age-groups, being higher in 0-10 and 3140years age-groups, which decreased thereafter in older subjects. However, there was a weak negative correlation between water exposure and age-groups of the respondents at $P<0.05$ (Table 4). 
The results in Table 4 represent a synopsis of correlation of schistosomiasis transmission variables and prevalence of UGS with gross haematuria serving as a proxy. There was a positive correlation of UGS with water exposure, sex and riverside contamination $(P<0.05)$. However, the disease correlated negatively with the age of the respondents. Fig. 2 indicates a strong association between haematuria and water exposure. The risk of developing haematuria was about 3 times in individuals exposed to the cercariae-infested water than in those not exposed (Odds Ratio (OR): 6.09, 95\% $\mathrm{Cl}, 2.825-13.131, P<0.0001$; Relative Risk (RR): $2.737,95 \% \mathrm{Cl}, 1.664-4.502, P<0.0001)$. The results presented in Fig. 3 indicate riverine water exposure and riverside anthropogenic contamination which promote schistosomiasis transmission in the study area. A lot of the participants involved in riverine water exposure were also linked to riverside contamination with human excreta.

\subsection{Healthcare-seeking Behaviour}

Fig. 4 represents results on healthcare-seeking behaviour of the respondents that presented with gross haematuria. The subjects preferred visiting traditional herbalists or taking a home-prepared herbal concoction for treatment of the ailment than other forms of healthcare. However, a significant number of respondents did not opt for any form of medication, orthodox or nonorthodox.

\section{DISCUSSION}

\subsection{Haematuria and Urogenital Schistosomiasis}

Urogenital schistosomiasis (UGS) is endemic in Kano State owing to the prevailing conducive geographical conditions that maintain the parasites in the snail intermediate hosts and the human host factors facilitating transmission. Our findings in this study revealed that UGS is endemic in the community given the high prevalence of gross haematuria (49.64\%) recorded from the study participants. In tandem with these findings, variable haematuria prevalence rates were reported in Kano State; $92.0 \%$ by Abdullahi [19], $52.75 \%$ by Duwa et al. [20], $63.3 \%$ by Ali et al. [21], 39.7\% by Dawaki et al. [17], $40.06 \%$ by Ali et al. [22] and $26 \%$ by Enabulele et al. [23], given the endemicity of UGS in Kano State owing to the presence of a large number of water bodies serving as suitable breeding grounds for the snail intermediate hosts of schistosomiasis. In all the above findings, the haematuria was significantly associated with prevalence and intensity of UGS. Ali et al. [21] further observed that chronic haematuria due to UGS may lead to a slow development of anaemia particularly in the presence of nutritional challenges. In a prevalence study conducted in the study area, Ahmad et al. [24] reported a $25 \%$ prevalence of UGS in school children. However, in this school-based study there was no report of haematuria among the study subjects. This would have given clear insights on the burden of Schistosoma haematobium infection in the community. However, given the high rate of contacts with contaminated water among schoolage children and adults in the community it would be possible to have a surge in haematuria prevalence which may indicate infection intensity where the bloody urine was due to UGS. Hence, there is the need for a comprehensive epidemiological survey in the study area to confirm the etiology of gross haematuria. Moreover, a large body of literature on the epidemiology of urogenital schistosomiasis revealed a strong association between $S$. haematobium infection intensity and terminal haematuria $[25,26,27]$. However, this study does not have the merit to conclude on the selfreported haematuria being associated with UGS since a lot of underlying renal pathologies could manifest as blood in the urine in which the blood stain may originate from either the upper or lower urinary tract (i.e. glomerular or non-glomerular in origin). Physiological disorders such as kidney stones, renal tubular acidosis and benign prostatic hyperplasia (BPH), and lower urinary tract infections are among the common causes of haematuria [28]. Further investigations like parasitological and imagistic methods, could differentiate the causes of haematuria. This study showed a high prevalence of reported haematuria among younger age-groups. This may be in connection to a naïve immunity to schistosome eggs deposits in the urothelial tissues which develop progressively as individuals age. In contrast, a study conducted in Sokoto State, Northwestern Nigeria revealed a $58 \%$ haematuria prevalence among adults in the study population [29].

\subsection{Water Contacts and Perceptions}

In this survey, all age-groups were exposed to contaminated water with different contact intensities for varied socioeconomic purposes. However, the rate of water contacts declined after the age of 40 . Majority of the respondents in 
Table 1. Prevalence of self-reported haematuria in relation to sociodemographic factors

\begin{tabular}{|c|c|c|c|c|c|c|}
\hline Characteristics & Category & Number examined & Number of Haematuria & $\%$ Prevalence & $x^{2}$ & $P$ value \\
\hline \multirow[t]{2}{*}{ Gender } & Male & $108(77.7)^{*}$ & 64 & 59.26 & 17.92 & $<0.001$ \\
\hline & Female & $31(22.3)$ & 5 & 16.13 & & \\
\hline Total & & $139(100)$ & 69 & 49.64 & & \\
\hline \multirow{7}{*}{ Age-group (years) $^{1}$} & $\leq 10$ & $20(14.39)$ & 11 & 55.00 & 43.25 & $<0.001$ \\
\hline & $11-20$ & $37(26.62)$ & 27 & 72.97 & & \\
\hline & $21-30$ & $26(18.71)$ & 13 & 50.00 & & \\
\hline & $31-40$ & $25(17.99)$ & 9 & 36.00 & & \\
\hline & $41-50$ & $18(12.95)$ & 5 & 27.78 & & \\
\hline & $51-60$ & $6(4.32)$ & 1 & 16.67 & & \\
\hline & $\geq 61$ & $7(5.04)$ & 3 & 42.86 & & \\
\hline Total & & $139(100)$ & 69 & 49.64 & & \\
\hline \multirow[t]{10}{*}{ Occupation } & Civil servants & $5(3.60)$ & 1 & 20.00 & 54.91 & $<0.001$ \\
\hline & Commercial laundry & $11(7.91)$ & 7 & 63.64 & & \\
\hline & Sand harvesting & $29(20.86)$ & 16 & 55.17 & & \\
\hline & Irrigation farming & $19(13.67)$ & 11 & 57.89 & & \\
\hline & Weaving/Tailoring & $10(7.19)$ & 2 & 20.00 & & \\
\hline & Trading & $12(8.63)$ & 5 & 41.67 & & \\
\hline & Fishing & $11(7.91)$ & 6 & 54.54 & & \\
\hline & Studentship & $31(22.30)$ & 19 & 61.29 & & \\
\hline & Housewifery & $6(4.32)$ & 1 & 16.66 & & \\
\hline & Others & $5(3.60)$ & 1 & 20.00 & & \\
\hline Total & & $139(100)$ & 69 & 49.64 & & \\
\hline \multirow[t]{5}{*}{ Education Status } & None & $23(16.55)$ & 12 & 52.17 & 22.16 & $<0.001$ \\
\hline & Almajiri school $^{2}$ & $39(28.06)$ & 24 & 61.54 & & \\
\hline & Primary school & $46(33.10)$ & 21 & 45.65 & & \\
\hline & Secondary school & $21(15.11)$ & 9 & 42.86 & & \\
\hline & Tertiary Institution & $10(7.19)$ & 3 & 30.00 & & \\
\hline Total & & $139(100)$ & 69 & 49.64 & & \\
\hline
\end{tabular}


Table 2. Sex-related perception of the cause of terminal haematuria

\begin{tabular}{|c|c|c|c|}
\hline \multirow{2}{*}{ Perceived Cause of Haematuria } & \multicolumn{2}{|c|}{ Number of Respondents } & \multirow[b]{2}{*}{ Total $(\%)$} \\
\hline & Male (\%) & Female (\%) & \\
\hline Infection & $10(9.26)$ & $4(12.9)$ & $14(10.07)$ \\
\hline Water Contact & $5(4.63)$ & $1(3.23)$ & $6(4.32)$ \\
\hline Supernatural Force & $3(2.78)$ & $5(16.12)$ & $8(5.76)$ \\
\hline Excessive Salt Intake & $46(42.59)$ & $12(38.71)$ & $58(41.73)$ \\
\hline Scorching Sun & $25(23.15)$ & $4(12.9)$ & $29(20.86)$ \\
\hline Unknown & $19(17.59)$ & $5(16.12)$ & $24(17.27)$ \\
\hline Total & $108(77.7)$ & $31(22.3)$ & $139(100)$ \\
\hline
\end{tabular}

Table 3. Age-related intensity of riverine water contact activities of the respondents

\begin{tabular}{|c|c|c|c|c|c|c|c|c|c|}
\hline Age group & $\mathrm{Ba}$ & Sw & $\mathrm{Cl}$ & PI & Sh & Ir & Fc & Fs & Total (\%) \\
\hline $0-10$ & ++ & +++ & - & ++ & - & + & + & + & $20(14.39)$ \\
\hline $11-20$ & ++ & ++++ & - & +++ & ++ & ++ & ++ & + & $37(26.62)$ \\
\hline $21-30$ & ++ & + & + & ++ & + & ++ & + & ++ & $26(18.71)$ \\
\hline $31-40$ & + & - & + & + & ++ & + & + & ++ & $25(17.99)$ \\
\hline $41-50$ & + & + & + & + & ++ & + & + & + & $18(12.95)$ \\
\hline $51-60$ & - & - & + & + & + & - & + & - & $6(4.32)$ \\
\hline$\geq 61$ & - & - & - & + & - & ++ & - & + & $7(5.04)$ \\
\hline Total & 21(15.11) & $28(20.14)$ & $10(7.2)$ & $22(15.8)$ & $21(15.11)$ & $16(11.5)$ & $15(10.8)$ & $6(4.32)$ & $139(100)$ \\
\hline
\end{tabular}

P<0.0001; Key: Ba-Bathing; Sw-Swimming; Cl-Commercial laundry; Pl-Personal laundry; Sh-Sand harvesting; Ir-Irrigation; Fc-Fetching; Fs-Fishing; Water contact: +Low; ++ moderate; +++High; ++++Intense; - Not involved

Table 4. Relationship between Urogenital schistosomiasis/gross haematuria and transmission variables

\begin{tabular}{|c|c|c|c|c|c|}
\hline Variable & Age & Sex & Gross Haematuria & Water Exposure & Riverside Contamination \\
\hline Age & 1.00 & & & & \\
\hline Sex & 0.28 & 1.00 & & & \\
\hline Gross Haematuria & $-0.132^{*}$ & $0.478^{*}$ & 1.00 & & \\
\hline Water Exposure & -0.11 & -0.099 & $0.300^{*}$ & 1.00 & \\
\hline Riverside Contamination & $0.125^{*}$ & $0.406^{*}$ & $0.282^{*}$ & $0.266^{*}$ & 1.00 \\
\hline
\end{tabular}




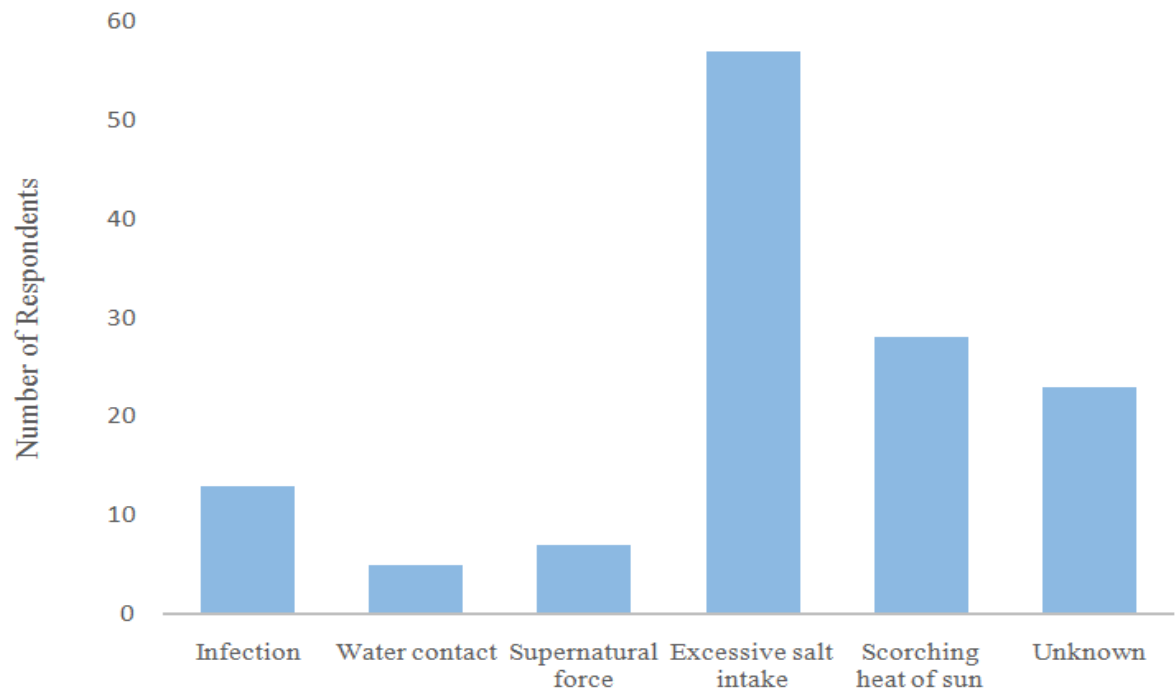

Fig. 1. Perception of the cause of gross haematuria among respondents

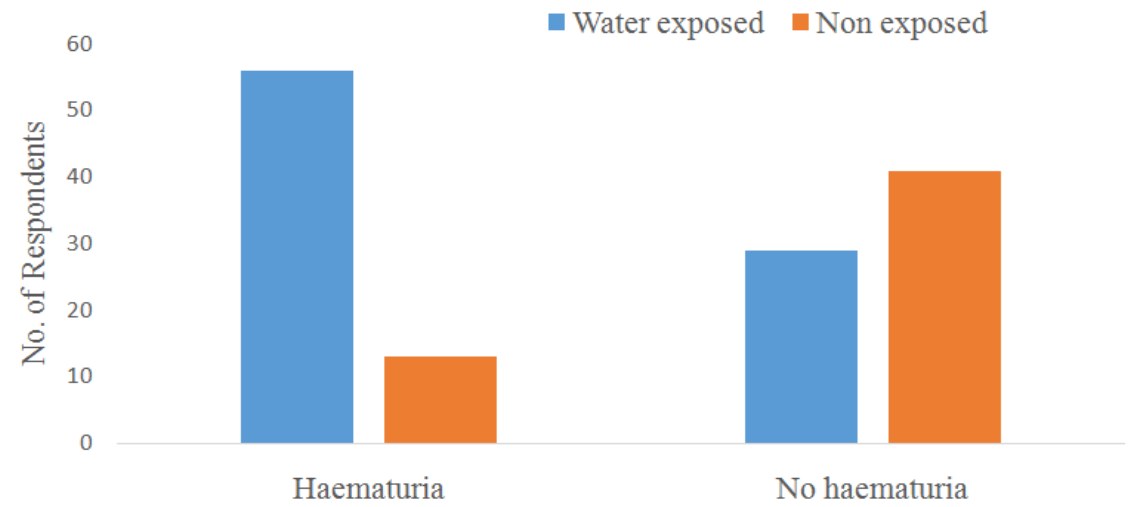

Fig. 2. Relationship between self-reported haematuria and riverine water exposure $P<0.0001$; OR: 6.09, 95\% Cl, 2.825-13.131, $P<0.0001 ; R R: 2.737,95 \%$ Cl, 1.664-4.502, $P<0.0001$

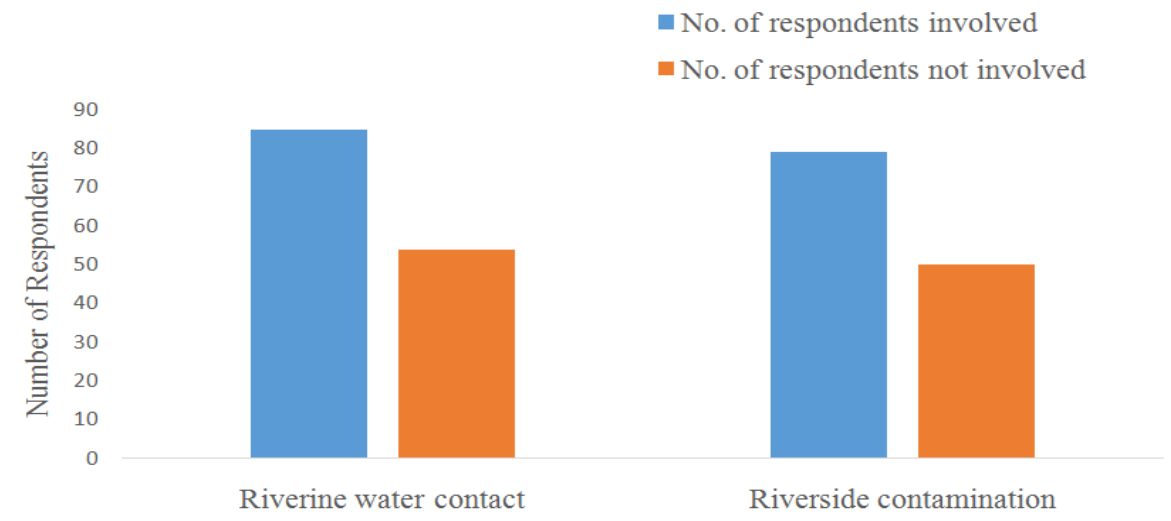

Fig. 3. Anthropogenic activities promoting schistosomiasis transmission 


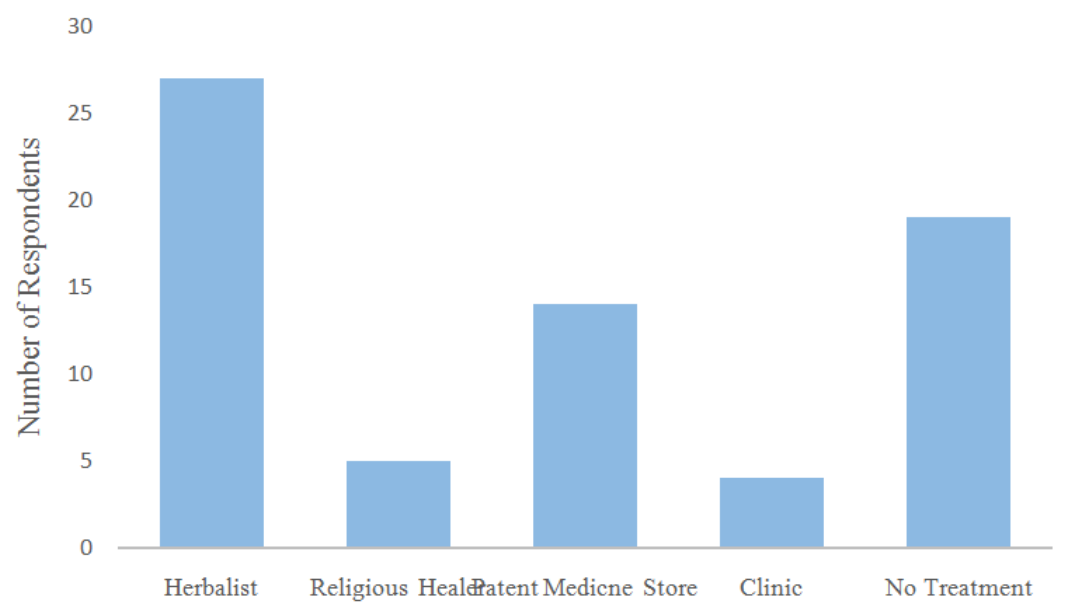

Fig. 4. Healthcare-seeking behaviour of respondents with self-reported haematuria

the age-group 21-30 years and below were involved in water contact activities for both recreational and occupational purposes, while the older age-groups were more restricted to occupational water contacts or have less WCAs. Similarly, Oso and Odaibo [18] observed an agerelated water-contact patterns with frequency of exposure to infested water reducing with old age. It could also be due to the development of immunity in the old people who may have contracted the disease in their young age. These conform with the findings of Ndams and Livingstone [13] and Inyang-Etoh et al. [30], who reported a decrease in schistosomiasis prevalence with advancing age as a result of reduced water contacts, and the development of immunity against Schistosoma haematobium infection. However, the higher gross haematuria observed among younger age-groups might coincide with high intensity of infection due to pronounced egg excretion in younger infections as immunological reactions around the eggs in chronic infections tend to limit their passage into the urinary system [31]. Moreover, younger age groups who are the most-at-risk population are prone to infection and reinfection even after conventional treatment with praziquantel. There is a wealth of data on schistosomiasis epidemiology which attest to the high frequency of water contact activities among younger agegroups as compared to older folks in endemic community. With availability of contaminated water in close proximity, school-aged children are most vulnerable to infection. In this study, a significant number of the respondents involved in riverine water exposure were also linked to riverside contamination. Older individuals involved in water contact activities (WCAs) did so mainly for occupational purpose. However, the frequency of water exposure among the older individuals was comparatively low. In certain communities, economic water contact was the most important type of WCAs, with the highest frequency during the early rainy season. This was found to be significantly associated with schistosomiasis transmission [32]. This finding is in tandem with that of Dawaki et al. [17] who suggested that an occupational risk posed by schistosomiasis could serve as a proxy for water contact patterns in endemic community.

Of the eight types of WCAs observed in this study, occupation-related activities such as sand harvesting, commercial laundry, irrigation farming and fishing, are common. Aboagye and Edoh [33] similarly found fishermen as the major occupational subgroup at high risk of Schistosoma infection, attributing it to regular contacts with contaminated water body. Although the findings in this research revealed a significant difference in self-reported haematuria between male and female respondents, we could not correlate gender with UGS owing to the small number of female respondents given the sociocultural settings of the Hausa community where females are hardly involved in outdoor activities, especially those that are water-related. In this study, female respondents were involved in WCAs for domestic chores. In a crosssectional study on schistosomiasis in Kano State, Dawaki et al. [17] attributed the gender inequity in terms of WCAs to religious and cultural practices where females are banned from recreational water exposure, such as swimming 
and bathing in an open water source, according to Islamic faith. In an observational study for WCAs in Wudil River, Ahmed and Bassey [16] reported that only a small number of females mostly girls of school-age were involved, and in which washing clothes and utensils was the most common. However, an association between Schistosoma haematobium infection and gender in favour of the males has been reported by several researchers $[11,19,34]$. Males are more exposed to the contaminated water sources $[17,24,35]$ and are therefore more vulnerable to infection. This long-held record of gender bias is prone to change due to differences in sociocultural settings [35]. Similarly, Salawu and Odaibo [36] reported a balanced prevalence of UGS in male and female preschool-aged children in Ogun State, Nigeria, probably due to equal rate of exposure to the infective water. Education, as a human host factor, is one of the social determinants that impact awareness and influence belief and perception on social scourges including those related to public health. Ali et al. [19] observed that the key factors responsible for UGS endemicity are low literacy level, lack of basic amenities, indiscriminate disposal of human sewage and high contacts with contaminated water sources. Moreover, low level of awareness in endemic community on the association between water exposure and schistosomiasis transmission would tend to increase the risk of disease transmission [11]. In a resource-poor setting, community awareness campaign is often recommended as a first intervention strategy to create the enabling environment for other strategies to thrive [17,37]. Similarly, misconceptions make health education intervention critical for successful schistosomiasis control campaign, since it will enable individuals to learn about the disease, recognize and manage their ailments [37]. In addition, health education intervention as an information, education and communication (IEC) strategy is important in preventing schistosomiasis transmission. However, educational intervention cannot unilaterally be effective in schistosomiasis control program, suggesting a need for implementation of an integrated and sustainable interventions [30].

\subsection{Environmental Contamination Healthcare-seeking Behaviour}

Studies have reported that about 2.3 billion people do not have decent toilets of their own. Without clean water, decent toilets and good hygiene, the impact of infectious diseases will be exacerbated [38]. Over 800 million children do not use improved sanitation facilities and therefore practice open field defecation and urination [39]. In our study, many of the study participants that were involved in the riverine water contact were also linked to riverside contamination. The reasons given for these contaminative activities were proximity to working site, urge for voiding and lack of access to toilet facility in the vicinity of their homes. The latter reason was more common among the Almajiri pupils and students who are mostly of the age range 0-20 years. This supports the findings of Ahmed and Bassey [16] who reported the involvement of males in open defecation in the study area and that school-age children tend to urinate indiscriminately while swimming or playing in the water. It was observed that human behaviour towards environmental contamination and lack of measures to improve sanitary conditions continue to predispose individuals to infection and reinfection in endemic communities $[9,40]$. In some rural communities, unhygienic methods of disposing human excreta create favourable conditions for the snail intermediate hosts to thrive [41]. In such resource-poor settings, Water, Sanitation and Hygiene (WASH) strategy would be a promising approach for schistosomiasis control.

The findings of this study revealed different levels of perception on the cause of $S$. haematobium infection among the study participants. While some of the respondents ascribed the disease to the intake of excessive salt, some misconceived that scorching sun was responsible for manifestation of the cardinal disease symptom, terminal haematuria, which is considered to be synonymous with UGS among the Hausa community. This finding is in agreement with the findings of Duwa et al. [20] who reported that taking too much salt was the perceived etiology of UGS in some dam-site communities in Kano State. Although, in our study a small percentage of the study participants correctly associated the disease with frequent exposure to contaminated water sources. There was no direct scientific correlation between excessive salt intake and UGS. But, the implication of this finding is that over-consumption of dietary salt could result in urodynamic irritative symptoms, such as excessive urination, frequent urination and the urge to urinate [42]. However, Bankir et al. [43] suggested that urine output per day is independent of the level of dietary salt intake. Another implication of excessive salt intake is the 
possibility of chloride ion overdose which could lead to the accumulation of hydrochloric acid in the bloodstream, causing renal tubular acidosis [44]. Haematuria is one of the frequent clinical presentations of renal tubular acidosis [45]. Therefore, in UGS-endemic settings excess salt along with other physio-pathological factors could precipitate haematuria. This maybe a compounding factor for the reported blood in the urine in this study. In-depth study should be conducted to determine if gross haematuria correlates with chronic dietary in-take of excess salt. The other popular perception that haematuria was due to a scorching sun may be in connection to a widely-held belief that chronic exposure to the heat of the tropical sun could result in the passing out of bloody urine especially among school-age children and the working young adults. Although, climate change has been linked to increasing schistosomiasis prevalence due to the effect of environmental temperature on metabolism and reproductive capacity of the snail hosts and the developing larval parasites therein [46,47], we could not explain if there is any scientific correlation of the respondents' perception with the changing climatic conditions that are a cause of a surge in the environmental temperature, especially the heat waves. In a verbal communication with majority of the respondents that complained of scratching their body after water exposure, they failed to associate the skin irritation to schistosomiasis transmission, further exposing a gross lack of awareness of the study participants on disease transmission dynamics. So far, there was no documented health education intervention in the study area. Earlier, Ali and Ndams [11] observed that a low community awareness on the link between exposure to contaminated water and schistosomiasis predisposes individuals to the disease transmission.

This study further revealed a preference of respondents to herbal medicine than orthodox therapy with conventional drugs which are prescribed at health clinics, or sold by patent medicine vendors. The respondents tend to visit traditional herbalists or take a home-prepared herbal concoction to provide treatment for the bloody urine. In poor rural settings with a known disease endemicity, individuals hardly patronize government clinics until an ailment becomes serious and chronic, because of their strong ties with traditional medicine practice, including spiritual healing and sorcery. Preference for herbal treatment to conventional chemotherapy has been a long-standing culture not only in Hausa community, but also in other parts of Nigeria. This was similarly observed by Anumudu et al. [48] that people in endemic communities have a recourse to phytotherapy for a belief that conventional drugs are repulsive to their traditional heritage. A good number of individuals in endemic communities prefer self-medication through patronizing local drug hawkers or consumption of herbal concoctions at home $[48,49,50]$. Moreover, a minority of the respondents attends government clinics for medication with $P Z Q$, which is the mainstay of UGS and other trematodiases, which is also available as over-the-counter drug at patent medicine stores. However, in spite of the prevailing haematuria, a larger percentage of the respondents were reluctant to seek treatment. This may imply incorrect perception on the cause of UGS as the major hindrance to seeking appropriate healthcare. Coupled with other prevailing risk factors, this would promote UGS transmission in the study area. It was suggested that control efforts and prevention measures against Schistosoma infections should be directed towards drawing physical and behavioural barriers between the human host and the snail vectors which involve a whole gamut of environmental management for vector control and behavioural reorientation on health implications of unprotected WCAs [51].

\section{LIMITATIONS OF THE STUDY}

We acknowledge that small sample size and a few number of female respondents characterised this study. However, this could be justified, considering the culture and tradition of Hausa/Fulani communities that detest gender mingling, as females are hardly involved in outdoor activities, especially water-based. Questionnaire was the major tool for the data collection, using self-reported haematuria as a proxy for UGS. There was no parasitological survey conducted.

\section{CONCLUSION}

This study confirms the presence of environmental and anthropogenic risk factors for schistosomiasis endemicity in the study area. While excessive salt intake and scorching sun are the most perceived causes of gross haematuria in the community, contacts with contaminated water and poor healthcare practice may indicate UGS transmission. Although, high prevalence of haematuria was recorded in this 
study, further research involving large sample size needs to be conducted to ascertain its etiology. It is pertinent to conduct a communitywide study on the epidemiology of schistosomiasis to assess the prevalence status and extent of terminal haematuria as the hallmark of UGS.

\section{CONSENT AND ETHICAL APPROVAL}

Before the commencement of the study, ethical approval was obtained from the Institutional Review Board (IRB), Kano University of Science and Technology, Wudil, after which a letter of introduction was delivered to the traditional authorities in the town for their consent. The authorities were informed on the aim of the research survey. The participants were duly informed on the aim of the study, and their consent sought. Only those participants who voluntarily agreed to be part of the study were recruited. Informed consent was obtained directly from the adult participants, while assent for non-adult participants was obtained, following the verbal consent of their parents or guardians. The participants were assured of confidentiality of the information given which would be used strictly for the purpose of the study.

\section{ACKNOWLEDGEMENT}

We acknowledge the logistic support provided by the Department of Biology, Kano University of Science and Technology, Wudil, and the cooperation of the study participants throughout the period of the study.

\section{COMPETING INTERESTS}

Authors have declared that no competing interests exist.

\section{REFERENCES}

1. Rollinson D. A wake up call for urogenital schistosomiasis: reconciling research effort with public health importance. Parasitology. 2009; 136:1593-610

2. Downs PW, Massoudi N, Dick A, Kabore A, Rothrock G, and Blough B. New tools for the schistosomiasis elimination toolbox: Barriers and opportunities for the development of a topical cercarial antipenetrant. Research Report, March 2017. RTI Press; 2017.

3. Weekly Epidemiological Report. Schistosomiasis. WER Sri Lanka-2019 $26^{\text {th }}$ $-01^{\text {st }} \cdot 2019 ; 46(5)$.
4. Miller $P$ and Wilson RA. Migration of the schistosomula of Schistosoma mansoni from the lungs to the hepatic portal system. Parasitology. 1980; 80:267-288

5. Cheever AW, Hoffmann KF and Wynn TA. Immunopathology of schistosomiasis mansoni in mice and men. Immunology Today. 2000;21(6):465-466.

6. Gryseels B, Polman K, Clerix J, Kestens L. Human Schistosomiasis. The Lancet. 2006; 368:1106-1118.

7. Cheesbrough M. District laboratory practice in Tropical countries part 1 . Cambridge University Press. 1998;236239.

8. Bamgbola OF. Urinary schistosomiasis. Pediatric Nephrology. 2014; 29:21132120.

DOI 10.1007/s00467-013-2723-1

9. Ali MU, Umar UA, Yahaya A, Lawal M, Danhassan MS. Human contamination and schistosome infection intensity in bulinid and planorbid snail vectors in Kadawa Irrigation Area, Kano State, Nigeria. International Journal of Tropical Disease \& Health. 2019;35(4):1-11. https://doi.org/10.9734/ijtdh/2019/v35i43 0131

10. Idris HS, Ajanusi OJ. Snail intermediate hosts and the etiology of human schistosomiasis in Katsina State, Nigeria. The Nigerian Journal of Parasitology. 2002; 23:145-152

11. Ali MU, Ndams IS. Awareness Levels of Water-Schistosomiasis Association of Two Irrigation Communities in Kano State, Nigeria. Biological and Environmental Sciences Journal for the Tropics. 2012;9(4):37-43.

12. Oladejo SO, Ofoezie IE. Unabated schistosomiasis transmission in Erinle River Dam, Osun State, Nigeria: Evidence of neglect of environmental effects of water development projects. Trop. Med. Int. Health. 2006;11(6):845-850

13. Ndams IS, Livingstone RS. Some patterns of schistosomiasis in a fishing settlement near Lake Geriyo, Jimeta-Yola. Nigerian Journal of Basic and Applied Sciences. 2000; 9:175-183

14. Olofin EA, Nabegu AB, Dambazau AM. Wudil within Kano region: a geographic synthesis. Department of Geography, Kano University of Science and Technology, Wudil; 2008. 
15. Dambazau AM. The geography of Wudil local government area. Wudil within Kano Region: A Geographical Synthesis Chapter 8 113-134, a publication of the Department of Geography, KUST Wudil. Adamu Joji Publishers, Sabon Titi, Kano; 2008.

ISBN 978-369067.1.

16. Ahmad MM, Getso BU and Ahmad UA. Water contact patterns and urinary schistosomiasis transmission among school children in endemic area of Wudil, Kano, Nigeria. IOSR Journal of Pharmacy and Biological Sciences. 2014;9(3) Version $\mathrm{V}: 01-04$

17. Dawaki S, Al-Mekhlafi HM, Ithoi I, Ibrahim $\mathrm{J}$, Abdulsalam AM, Ahmed A, Sady $\mathrm{H}$ et al. Prevalence and risk factors of schistosomiasis among Hausa communities in Kano State, Nigeria. Rev. Inst. Med. Trop. Sao Paulo. 2016; 58:54

18. Oso OG, Odaibo AB. Human water contact patterns in active schistosomiasis endemic areas. Journal of Water and Health. 2020;18(6):946-955

19. Abdullahi J. Low cost management of urinary schistosomiasis in endemic setting. Unpublished M. Sc Thesis. Department of Biological Sciences, Bayero University, Kano, Nigeria; 2005.

20. Duwa MR, Oyeyi YI, Bassey SE. Prevalence and intensity of urinary schistosomiasis among primary school pupils in Minjibir Local Government Area of Kano State. Bayero Journal of Pure and Applied Sciences. 2009;2(1):75-78.

21. Ali MU, Umar AU, Hamza IU, Yahaya A, Dambazau SM. Schistosoma haematobium infections: prevalence and morbidity indicators in communities around Wasai Dam, Minjibir, Kano State, Northern Nigeria. International Journal of Tropical Disease and Health. 2016;17(2):1-8 https://doi.org/10.9734/IJTDH/2016/2344 8

22. Ali MU, Umar UA, Inuwa MS, Sabo $M$, Gobir HM, Bala MA, Luka, SA, Ndams IS. Prevalence, Predictors and Risk Factors of Urogenital Schistosomiasis among Hausa Dam-site Communities, Kano State, Nigeria. $1^{\text {st }}$ International Conference on One Health, Kano 2019, $9^{\text {th }}-14^{\text {th }}$ December, 2019, Bristol Palace Hotel, Farm Center, Kano State, Nigeria; 2019.

23. Egie E. Enabulele, Roy N. Platt, Ehizogie Adeyemi, Esther Agbosua, Martin S.O.
Aisien, Oluwaremilekun G. Ajakaye, Mahmud U. Ali, Ebube C.Amaechi, Tolulope E. Atalabi, TimothyAuta, Oluwaseun B. Awosolu Adamu G. Dagona, Omoyemwen Edo-Taiwo, Chika E.P.Ejikeugwu, Christopher Igbeneghu, Victor S. Njom, Mary-Kate N. Orji, Funso O.P. Oyinloye, Habibat J. Ozemoka, Uchenna I. Ugah, Timothy JC, Anderson. Urogenital schistosomiasis in Nigeria post receipt of the largest single praziquantel donation in Africa. Acta Tropica. 2021;219. https://doi.org/10.1016/j.actatropica.2021 .105916

24. Ahmad MM, Bassey SE. Study on the Pattern of Water Contact Activities in Schistosomiasis Endemic Area of Wudil, Kano, Nigeria. Biological and Environmental Sciences Journal for the Tropics. 2010;7(2):176-180

25. Atalabi TE, Adubi TO, Lawal U. Rapid mapping of urinary schistosomiasis: An appraisal of the diagnostic efficacy of some questionnaire-based indices among high school students in Katsina State, northwestern Nigeria. PLOS Neglected Tropical Diseases. 2017;11(4): e0005518.

26. Medecins Sans Frontieres. Parasitic diseases: Schistosomiases; 2021.

Available:https://medicalguidelines.msf.org /viewport/CG/english/schistosomiases16689787.html.

Accessed on April 19, 2021

27. Mascarenhas A, Castro I. A rare case of hematuria. Einstein. 2011;9(1 Part 1):81-3

28. Bolenz C, Schroppel B, Eisenhardt A, Schmitz-Drager BJ, Grimm M. The Investigation of Hematuria. Dtsch Arztebl Int. 2018; 115:801-7

29. Bello A, Ojimoh A, Shittu SB, Hudu SA. Prevalence of urinary schistosomiasis and associated haemato-proteinuria in Wurno Rural Area of Sokoto State, Nigeria. Orient Journal of Medicine. 2014;26(34):114-121

30. Inyang-Etoh PC, Anyanwu CJ, Udonkang $\mathrm{MI}$ and Equali VI. Cytological findings in urine of adult residents of urinary schistosomiasis endemic community in Cross River State, Nigeria. British Journal of Medicine \& Medical Research. 2015;8(11): 948-955.

31. Tukur A, Galadima M. Epidemiological study of schistosomiasis in the Bakolori Irrigation Project Area of Zamfara State, 
Nigeria: Prevalence and intensity of Schistosoma haematobium infection. The Nigerian Journal of Parasitology. 1998;19 :73-75.

32. Hassan AO, Amoo AOJ, Akinwale OP, Deji-Agboola AM, Adeleke MA et al. Human water contact activities and urinary schistosomiasis around Erinle and Ekoende Dams. Global Advanced Research Journal of Medicine and Medical Sciences. 2012;1(4):077-084

33. Aboagye IF, Edoh D. Investigation of the risk of infection of urinary schistosomiasis at Mahem and Galilea communities in the greater Accra region of Ghana. West African Journal of Applied Ecology. 2009;15.

34. Adomeh DI. Prevalence of Schistosoma haematobium in parts of Yobe State, Nigeria. Nig. J. of Med. Lab. Sci. 1998; 7:11-16.

35. Rudge JW, Stothard JR, Basanez MG. Micro-epidemiology of urinary schistosomiasis in Zanzibar: Local risk factors associated with distribution of infections among schoolchildren and relevance for control. Acta Tropica. 2008; 105:45-54.

36. Salawu OT, Odaibo AB. Urogenital schistosomiasis and urological assessment of hematuria in preschool-aged children in rural communities of Nigeria. Journal of Pediatric Urology. 2014; 10:8893.

37. Ekeh HE, Adeniyi JD. Health education strategies for tropical disease control in school children. J Trop Med Hyg. 1988; 91:55-9.

38. Water Aid. Everyone, everywhere 2030: Our global strategy, 2015-2022. Water Aid; 2019.

Available: www.wateraid.org Accessed on April 10, 2021.

39. Water Aid. Out of Order: The state of the world's toilets. WaterAid; 2017.

Available:www.wateraid.org Accessed on November 25, 2017.

40. Liu L, Yang G, Zhu H, Yang K, Ai L. Knowledge of, attitudes towards, and practice relating to schistosomiasis in two subtypes of a mountainous region of the People's Republic of China. Infectious Diseases of Poverty. 2014; 3:16.

41. Akullian AN. Spatial Patterns of Schistosomiasis: A watershed approach to measuring $S$. japonicum environmental risk and human and animal disease outcomes. B.Sc. Thesis, Brown University, Rhode Island, USA. 2007;5.

42. He FJ, Markandu ND, Sagnella GA, MacGregor GA. Effect of salt intake on renal excretion of water in humans. Hypertension. 2001; 38:317-320

43. Bankir L, Perucca J, Norsk P, Bouby N, Damgaard M. Relationship between Sodium Intake and Water Intake: The False and the True. Annals of Nutrition and Metabolism. 2017;70(suppl 1):51-61

44. Young SL, Hage MC. Li, J. Another Case of Excessive Caffeine and Hypokalemia in Pregnancy. Journal Obstetrics and Gynecology. 2001;98(5):874.

45. Gabriel R. Renal Medicine. Bailliere Tindall, London. 1977;168-169.

46. Ali MU, Ndams IS. Distribution of snail intermediate hosts of schistosomiasis in human water contact points along Kadawa irrigation canals, Kano State, Nigeria. Biological and Environmental Sciences Journal for the Tropics. 2012;9(2):169-175.

47. Adekiya TA, Aruleba RT, Oyinloye BE, Okosun KO, Kappo AP. The Effect of Climate Change and the SnailSchistosome Cycle in Transmission and Bio-Control of Schistosomiasis in subSaharan Africa. International Journal of Environmental Research and Public Health. 2020; 17:181.

DOI: 10.3390/ijerph17010181

48. Anumudu $\mathrm{Cl}$, Onile $\mathrm{OS}$, Awobode $\mathrm{H}$, Gboyega-Tokunbo A, Oladele $A A$ and Chouvwen CO. Socio-cultural and environmental determinants of a proposed schistosomiasis health education intervention in Eggua, Nigeria. Journal of Behavioral Health. 2019;8(3):92-100

49. Dawaki S, Al-Mekhlafi HM, Ithoi I, Ibrahim $\mathrm{J}$, Abdulsalam AM, Ahmed A, Sady $\mathrm{H}$ et al. The menace of schistosomiasis in Nigeria: Knowledge, attitude, and practices regarding schistosomiasis among rural communities in Kano State. PLoS ONE. 2015;10(11):e0143667

50. Ali MU, Umar UA, Inuwa MS, Sabo M, Gobir HM, Bala MA, Luka, SA and Ndams IS. Perception and healthcare-seeking behaviour of schistosomiasis-endemic communities in Kano State, Nigeria. $1^{\text {st }}$ International Conference on One Health, Kano 2019, $9^{\text {th }}-14^{\text {th }}$ December, 2019, 
Bristol Palace Hotel, Farm Center, Kano State, Nigeria; 2019.

51. Ali MU, Ndams IS. Human Schistosoma infections: Intensity versus water contact patterns among irrigation communities in Kano State, Nigeria. Biological and Environmental Sciences Journal for the Tropics. 2013;10(3):120-124.

(c) 2021 Umar et al.; This is an Open Access article distributed under the terms of the Creative Commons Attribution License (http://creativecommons.org/licenses/by/4.0), which permits unrestricted use, distribution, and reproduction in any medium, provided the original work is properly cited.

Peer-review history:

The peer review history for this paper can be accessed here: https://www.sdiarticle4.com/review-history/65690 